\title{
Decomposition Analysis on Dematerialization for the Further Development of Circular Economy
}

\author{
Lei WANG \\ Economy Research Center \\ Nankai University \\ Tianjin, P.R.China \\ nkwanglei@yahoo.cn
}

\author{
Hui-ming LI \\ Economy Research Center \\ Nankai University \\ Tianjin, P.R.China \\ lihm@nankai.edu.cn
}

\begin{abstract}
According to the connotation of dematerialization, this paper states that dematerialization plays an important role in deepening the development of circular economy, and maintaining balance and function of the eco-economic system. On the basis of Laspeveres Index and the Complete decompose model, the paper tries to decompose the factors related to the dematerialization, and evaluates the dynamic effect on the material saving brought by material use intensity, economic structure and economic scale, especially the rebound effect and dematerialization effect. The author also makes an empirical research on the energy consumption during the period of 1985 to 2006 in China, calculates the effect of economy scale and material use intensity in the change of energy consumption, and analyzes the impact of economic structure adjustment on energy saving. The result shows that expansion of economy scale is the major factor driving the energy consumption. The total amount of 21-year energy consumption was $23.6 \times 10^{8}$ tce. The improper economic structure increases the energy consumption by $1.82 \times 10^{8}$ tce. From the data, it can be concluded that the economic structure adjustment was playing a negative role in the process of energy saving. The combined impact of economic scale and economic structure cause the increase of energy consumption. The impact of material use intensity on energy consumption was consistent, especially, the ratio of material use intensity of the second industry to the total was the biggest and beyond $\mathbf{7 6}$ percent, and first industry and the tertiary industry had the relatively smaller ratio. The energy saving brought by dematerialized effect was $9.67 \times 10^{8}$ tce, but this saving effect was traded off by expansion effect of economic scale, and thus the rebound effect of energy consumption was obvious. Therefore, the research relating to the energy consumption should focus on decreasing energy intensity in the second industry and improving energy utilization efficiency. In addition, we should put stress on the saving effect brought by the proper adjustment on economic structure and control the re-bound effect, meanwhile adjust and control the path and pattern of material flow by material intensity relative index. It also suggested estimating the level of Circular Economy by the absolute dematerialization index to promote the harmonious interaction between the economic development and ecological environment.
\end{abstract}

Keywords-dematerialization; complete decomposition method; material use intensity; rebound effect; Circular Economy

\section{Introduction}

Dematerialization, an important role playing in the sustainable development strategy, is a new research thinking put forward for solving the contradictions between natural resources shortage and environment pollution. Since last century, dematerialization has been differently defined by scholars at home and abroad: In 1988 Colombo, U. thought dematerialization was a certain result of economic development. It showed the static and stable characteristic of material demands [1]; In 1989 Labys, W. C. and Waddel, L. M. considered dematerialization was the course that relevant lowquality materials could be displaced by high-quality or hightechnical ones as the industry developed[2]; In 1988 Robert Herman, Siamak Ardekani, and Jesse Ausubel primarily defined dematerialization as the decline over time in the weight of materials used in industrial end products or in the "embedded energy" of the products[3]; In 1993 Bernardini, O. and Galli, R. regarded dematerialization as reduction in use intensity of raw materials (energy and materials) in economic activities and its indicator was the ratio of material consumption to GDP(gross domestic product) [4]; In 1996 Wernick, I. and others held that dematerialization referred to the absolute or relative reduction in the quantity of materials required to serve economic functions[5]; In $2000 \mathrm{CHEN}$ Xiaoqiu saw dematerialization as the absolute or relative reduction in the material usage of unit output value or the quantity of associated wastes[6]. According to the extent of changes in economic growth and material consumption, "decoupling" was classified as relative decoupling and absolute decoupling. Relative decoupling means that economic growth and resource use are decoupled to some extent in a certain period of time. In other words, materials use is growing, but less steep than the growth of the economy. When the economy is growing at the same time, gradually reduce material consumption and pollutant emissions. Coupled breakdown of a relationship between the two, called absolute "decoupling." Absolute decoupling would take place if the growth of the materials use would be negative [7].

\section{DEMATERIALIZATION IS KEY POINT OF CIRCULAR DEVELOPMENT}

\section{A. Balance and function maintaining of the eco-economic system}

The economic development of human being's society depends much on material consumption. As a factor of economic impetus, the material consumption, however, could accelerating in exhausting the natural resources, damaging the 
ecology and causing a series of environmental problems, by which economic development would be seriously hindered. Services are the final income of all the economic activities. It is the stocks existing by different forms that directly provide services, but the throughputs themselves don't. The stock is maintained or increased by the throughput, and the number of throughput decides the stock scale it could maintain.

Thus, in order to maintain the equilibrium and function of eco-economic system, dematerialization of economic development should be ensured which the improvement of resource productivity, and reduction of material throughput and energy throughput, i.e. the input-output scale of the material and energy from the environmental system to economic system, go in pace with economic growth.

\section{B. Dematerialization and circular economy}

Our Common Future was published by the World Commission on Environment and Development in 1987, it was widely adopted that sustainable development could be defined as satisfactory needs of modern people, but it cannot be achieved without adequate supplies of energy in suitable forms for later generations. This definition literally focuses on the right of developing to modern and later generations equally, however, the real meaning is how to distribute rare natural capital to them. Natural capitals offer human beings products and services. People enjoy from them and the welfares rise[10]. So the key point of sustainable development is that constant natural capital stock should be kept for later generations to have an equal opportunity in creating fortunes and promoting welfares.

As a fundamental change to the traditional growth pattern, circular economy is a completely new pattern with the character of low consumption, low emissions and high efficiency, which is consistent with the idea of sustainable development. CE's nature is the harmony between human and nature, and the win-win situation between economy and environment which is fully reflected and justified by "decoupling" focusing on dematerialization. Decoupling gives people a feasible and practical way to achieve CE so that $\mathrm{CE}$ is no longer an ideal assumption but a perspective.

\section{METHODOLOGY}

Undoubtedly, the reduction in material consumption intensity would result in decrease of material, but dematerialization is more than a problem of technology. The factors of changing the economic distribution and expanding the economic scale could both influence the result of dematerialization. The estimating result of dematerialization should be an absolute numerical value, rather than a relevant ratio value of material consumption produced by unit economy.

By analyzing the connotation and framework of dematerialization, I think, our research could not be limited on whether dematerialization happens. The more important thing is to analyze how the factors such as technology progress, economic distribution changing, economic scale expanding and so on impact and effect the material decrease, by which decrease-effect and rebound-effect caused by dematerialization could be computed.

\section{A. Multiplication Principle}

There is a certain relationship between factors $X_{i}(i=1, \ldots, n)$ and effect $\mathrm{Y}$. In the time interval $[0 \rightarrow t], X_{i}^{0} \rightarrow X_{i}^{t}=X_{i}^{0}++\Delta X_{i}(i=1, \ldots, n), \Delta x_{i}$ is the increment of factor $X_{i} . Y^{0} \rightarrow Y^{t}$ and $\Delta y$ is the increment of Y. If the relationship between increments $\Delta X_{i}$ of factor $X_{i}$ and the increment $\Delta y$ of the effect $\mathrm{Y}$ is a relationship of multiplication, i.e. $\Delta y=\prod_{i}^{n} \Delta X_{i}$. The contribution of the change in factor $X_{i}$ to the change in effect $\mathrm{Y}$ is determined by $\frac{\Delta y}{n}$ or $\frac{\prod_{i}^{n} \Delta X_{i}}{n}$. This is the multiplication principle: "jointly created and equally distributed" [8].

\section{B. Complete Decomposition Method}

According to the principle of "jointly created and equally distributed", the changing of target volume V would be impacted by every factors, at the same time, it would be impacted by the interaction effects among factors. Obviously, the longer the observation period, the greater value these remaining terms gain. Thus, omitting these remaining terms would distort the results. Therefore,

$$
\begin{aligned}
X_{i-\text { effect }}= & \frac{V^{0}}{x_{i}^{0}} \Delta x_{i}+\sum_{j \neq i} \frac{V^{0}}{2 x_{i}^{0} x_{j}^{0}} \Delta x_{i} \Delta x_{j}+\sum_{j \neq \gamma \neq i} \frac{V^{0}}{3 x_{i}^{0} x_{j}^{0} x_{\gamma}^{0}} \Delta x_{i} \Delta x_{j} \Delta x_{\gamma}+\cdots \cdots \\
& +\frac{1}{n} \Delta x_{1} \Delta x_{2} \Delta x_{3} \cdots \Delta x_{n}
\end{aligned}
$$

\section{Measurement of Dematerialization}

According to the complete decomposition model, change in energy use in the preceding 2 years can be attributed to three effects. The first is the energy intensity effect $\left(\mathrm{W}_{\text {Ieffect }}\right)$ (see formula (2)), which reflects the contribution of change in energy intensity to the change in energy use. The second is the structural shift effect $\left(\mathrm{S}_{\text {effect }}\right)$ (see formula $\left.(3)\right)$, which reflects the contribution of change in economic structure to the change in energy use. Finally, the economic activity effect $\left(\mathrm{GDP}_{\text {effect }}\right)$ (see formula (4)), which reflects the contribution of change in economic scale to the change in energy use [9].

$$
\begin{aligned}
& W_{t-\text { effoct }}=\sum_{i=1}^{n}\left(\Delta I_{i}\right) \times S_{i}^{\prime} \times G D P^{\prime}+\frac{1}{2} \sum_{i=1}^{n} \Delta I_{i} \times\left(\Delta S_{i} \times G D P^{\prime}+S_{i}^{\prime} \times \Delta G D P\right) \\
& +\frac{1}{3} \sum_{i=1}^{n} \Delta I_{i} \times \Delta S_{i} \times \Delta G D P \\
& W_{S-\text { deftec }}=\sum_{i=1}^{n} I_{i}^{\prime} \times \Delta S_{i} \times G D P^{\prime}+\frac{1}{2} \sum_{i=1}^{n} \Delta S_{i} \times\left(\Delta I_{i} \times G D P^{\prime}+I_{i}^{\prime} \times \Delta G D P\right) \\
& +\frac{1}{3} \sum_{i=1} \Delta I_{i} \times \Delta S_{i} \times \Delta G D P \\
& W_{\text {gDP }} \text {-dject }=\sum_{i=1}^{n} I_{i}^{i} \times S_{i} \times \Delta G D P \quad+\frac{1}{2} \sum_{i=1}^{n} \Delta G D P \quad \times\left(\Delta I_{i} \times S_{i}^{i}+I_{i}^{i} \times \Delta S_{i}\right) \\
& +\frac{1}{3} \sum_{i=1} \Delta I_{i} \times \Delta S_{i} \times \Delta G D P \\
& \Delta W=W^{t+1}-W^{t}=W_{i-\text { effect }}+W_{S-\text { effect }}+W_{G D P-\text { effect }} \\
& \text { Material saving }=-\left(W_{I-\text { effect }}+W_{S-\text { effect }}\right)
\end{aligned}
$$


Rebound effect $=W_{G D P-e f f e c t}$-saving effect

\section{DEMATERIALIZATION OF ENERGY USE IN CHINA}

The Aim of this research is to uncover how does the three factors; economy scale, economy structure and technological progress influence the over all energy consumption at the country level. The proposed analytical procedure relies on the refined Laspeyres (formula (2)-(6)) model. The demonstration analysis using the statistic data from the National Bureau of Statistics (1986-2007) to get the Energy Consumption Intensity of each industry Ii (see table 1)。(Annual GDP were converted to the real GDP at the price of 1978)

TABLE I. DATA OF ENERGY CONSUMPTION FROM 1985 TO 2006

\begin{tabular}{|c|c|c|c|}
\hline YEAR & $\begin{array}{c}\text { energy } \\
\text { consumption of } \\
\text { primary } \\
\text { industry }\end{array}$ & $\begin{array}{c}\text { energy } \\
\text { consumption } \\
\text { of secondary } \\
\text { industry }\end{array}$ & $\begin{array}{c}\text { energy } \\
\text { consumption } \\
\text { of tertiary } \\
\text { industry }\end{array}$ \\
\hline 1985 & 2.53 & 15.16 & 3.44 \\
\hline 1986 & 2.62 & 14.62 & 3.25 \\
\hline 1987 & 2.59 & 13.87 & 3.01 \\
\hline 1988 & 2.66 & 12.95 & 2.92 \\
\hline 1989 & 2.60 & 13.13 & 2.93 \\
\hline 1990 & 2.48 & 12.96 & 2.93 \\
\hline 1991 & 2.54 & 12.03 & 2.91 \\
\hline 1992 & 2.39 & 10.61 & 2.80 \\
\hline 1993 & 2.15 & 9.47 & 2.88 \\
\hline 1994 & 2.23 & 8.62 & 2.63 \\
\hline 1995 & 2.29 & 8.25 & 2.34 \\
\hline 1996 & 2.27 & 7.68 & 2.37 \\
\hline 1997 & 2.26 & 6.91 & 2.28 \\
\hline 1998 & 2.14 & 6.02 & 2.30 \\
\hline 1999 & 2.09 & 5.34 & 2.31 \\
\hline 2000 & 2.03 & 4.82 & 2.22 \\
\hline 2001 & 2.13 & 4.58 & 2.12 \\
\hline 2002 & 2.16 & 4.62 & 2.06 \\
\hline 2003 & 2.18 & 4.92 & 2.14 \\
\hline 2004 & 2.34 & 5.20 & 2.27 \\
\hline 2005 & 2.31 & 5.14 & 2.25 \\
\hline 2006 & 2.32 & & \\
\hline
\end{tabular}

a. tce/ 10,000 yuan of GDP

TABLE II. DECOMPOSITION FOR CHANGES OF ENERGY USE IN CHINA DURING 1985 AND 1995

\begin{tabular}{|c|c|c|c|c|c|}
\hline \multirow{2}{*}{ Period } & \multicolumn{3}{|c|}{ Decomposition effect } & \multirow{2}{*}{$\begin{array}{c}\text { Rebound } \\
\text { effect }\end{array}$} & $\begin{array}{c}\text { Effect of } \\
\text { reduction }\end{array}$ \\
\cline { 2 - 4 } & $\begin{array}{c}\mathbf{W}_{\text {GDP- }} \\
\text { effect }\end{array}$ & $\mathbf{W}_{\text {I-effect }}$ & $\begin{array}{c}\mathbf{W}_{\text {S- }} \\
\text { effect }\end{array}$ & & 1750 \\
\hline $\begin{array}{c}1985- \\
1986\end{array}$ & 5743 & -2214 & 464 & 3993 & 2944 \\
\hline $\begin{array}{c}1986- \\
1987\end{array}$ & 7896 & -3695 & 750 & 4952 & 2 \\
\hline
\end{tabular}

\begin{tabular}{|c|c|c|c|c|c|}
\hline $\begin{array}{c}1987- \\
1988\end{array}$ & 8302 & -4398 & 1249 & 5154 & 3148 \\
\hline $\begin{array}{c}1988- \\
1989\end{array}$ & 3208 & 849 & -170 & 3888 & -680 \\
\hline $\begin{array}{c}1989- \\
1990\end{array}$ & 2959 & -1125 & -281 & 1553 & 1406 \\
\hline $\begin{array}{c}1990- \\
1991\end{array}$ & 8288 & -5235 & 1833 & 4886 & 3402 \\
\hline $\begin{array}{c}1991- \\
1992\end{array}$ & 13226 & -10170 & 2689 & 5744 & 7482 \\
\hline $\begin{array}{c}1992- \\
1993\end{array}$ & 13767 & -9325 & 2394 & 6836 & 6931 \\
\hline $\begin{array}{c}1993- \\
1994\end{array}$ & 13839 & -9136 & 2250 & 6953 & 6886 \\
\hline $\begin{array}{c}1994- \\
1995\end{array}$ & 12228 & -5482 & 1362 & 8108 & 4120 \\
\hline $\begin{array}{c}1995- \\
1996\end{array}$ & 11841 & -7050 & 1012 & 5803 & 6038 \\
\hline $\begin{array}{c}1996- \\
1997\end{array}$ & 11296 & -11207 & 483 & 571 & 10725 \\
\hline $\begin{array}{c}1997- \\
1998\end{array}$ & 9424 & -13854 & 447 & -3984 & 13407 \\
\hline $\begin{array}{c}1998- \\
1999\end{array}$ & 8880 & -11302 & 149 & -2272 & 11153 \\
\hline $\begin{array}{c}1999- \\
2000\end{array}$ & 9762 & -10249 & 323 & -164 & 9926 \\
\hline $\begin{array}{c}2000- \\
2001\end{array}$ & 9488 & -5412 & 27 & 4103 & 5385 \\
\hline $\begin{array}{c}2001- \\
2002\end{array}$ & 11230 & 262 & 210 & 11701 & -472 \\
\hline $\begin{array}{c}2002- \\
2003\end{array}$ & 14786 & 8200 & 989 & 23976 & -9189 \\
\hline $\begin{array}{c}2003- \\
2004\end{array}$ & 16699 & 9625 & 457 & 26781 & -10082 \\
\hline $\begin{array}{c}2004- \\
2005\end{array}$ & 19698 & -2346 & 628 & 17980 & 1718 \\
\hline $\begin{array}{c}2005- \\
2006\end{array}$ & 23421 & -3450 & 985 & 20956 & 2465 \\
\hline $\begin{array}{c}1985- \\
2006\end{array}$ & 235981 & -96714 & 18251 & 157518 & 78463 \\
\hline
\end{tabular}

a. tce/ 10,000 yuan of GDP

The expansion of the economic scale directly affects the consumption of the energy, meanwhile the good adjustment of the material use intensity and the economic structure is the major effect of the dematerialization index, i.e. the saving effect equals to the sum of the energy effect and the structure effect. During 1985 and 2006, the economic scale plays the significant role among the driving effects of the energy consumption. The total amount of energy consumption in 21 years is $23.6 \times 10^{8}$ ton of coal; the energy saving brought by dematerialized effect was $9.67 \times 10^{8}$ ton of coal; and the improper economic structure increases the energy consumption by $1.82 \times 10^{8}$ ton of coal. The total effect of the structure effect and the economic scale effect leads the increase of the energy consumption of China, the real consumption in these 21 years is $15.75 \times 10^{8}$ ton of coal.

As shown in Table 1, during 1985 to 2006, the energy consumption of China experienced a decrease expect for some year. The energy consumption of the first industry and the third industry keeps the small decrease trend. Meanwhile the second industry showed an accelerated decrease trend; and after 1996, the decrease slow down. By 2004, the energy consumption suddenly increased, this tendency agreed with the total energy consumption of China.

During 1985 to 2006, the decrease of the energy consumption caused by the improvement of the technology 
lead the saving effect in some content, especially in the second industry. Wu's research shows that the ratio of material use intensity of the second industry to the total was the biggest and beyond 76 percent. But this saving effect was traded off by expansion effect of economic scale, and thus the rebound effect of energy consumption was obvious. Thus appears the state of dematerialization, i.e. the increase of the economics is greater than the consumption of the materials.

Between 2000 and 2004, the energy consumption caused by the expansion of the economic scale suddenly increased. The main reason of this phenomenon is decreasing trend of the energy strength slowed down during this period. But after 2004, this trend increased (as shown in Table 1); mean time, the driving effect of the dematerialization disappear, overmaterialization effect strengthened. The curve of the energy strength affects the energy rebound curve, and makes it climbed up. In addition of the increase of the materialization effect of the economic structure, the energy consumption highly raises during this period.

Due to lack of the dematerialization effect caused by the unbalance of the industry structure of China, expected for some years, the effect of the adjustment of the industry structure to the energy consumption is positive, it increased the energy consumption by the means of over-materialization effect. In the industry structure of China, the ration of the second industry is over-whelmed, especially for those high energy consumption industries. The development of third industry, which is high added value and low energy consumption, is slow. As shown in Figure 4 , in total, the rebound effect of the dematerialization is far larger than the energy saving effect in China. This result is closely related to the effect that China is a developing country. During this period, the expansion of economic scale directly leads the increase of the material demand, thus the appearance of the rebound effect is reasonable. Thus, the major issue that China facing is how to change the situation that the economic grow up costs the environment during this low-grow economic period. The possible solution is using adjustment of the economic developing method and the energy saving effect in the technology improvement and structure effect.

\section{CONCLUSION}

Circular economy, a new national strategy combining economic development and environment protection, aims at maintaining the balance and function of eco-economic system, by which dematerialized development could be realized as the relationship of coupling between economic growth and material consumption breaks.

Thus, it is helpful to further developing circular economy, taking dematerialization as an important measure criterion of regional economic development level, with flow route and manner of materials adjusted by material usage intensity standard, as well as development level of circular economy evaluated by standard of material absolute decrement. Besides, while material usage intensity is promoted and material decrement is driven, decrement effect after bettering economic structure should be concerned. Leading industry would be decided by regional resource natural endowment and environmental quality level. Rebound effect would be reduced and restrained by attaching great importance to inter-regional division and cooperation of industries, exerting decrement effect driven by bettering economic structure. Positive interaction between Industrial development and ecoenvironment could be realized as a result.

\section{REFERENCES}

[1] Colombo, U. The technology revolution and the restructuring of the global economy. Globalization of Technology: International Perspectives. J. H. Muroyama and H. G. Stever, eds.: Washington, D.C.: National Academy Press, 1988.23-31

[2] Labys, W. C. and Waddell, L. M.. Commodity lifecycles in US materials demand. Resources Policy. 1989,15:238-251.

[3] Herman, R., Arkekani, S. A. and Ausubel, J. H. Dematerialization. In: Ausubel, J. H. and Sladovich, H. E. (Editors), Technology and Environment. Washington, D.C.: National Academy Press, 1989.50-69.

[4] Bernardini, O. and Galli, R. Dematerialization: long-term trends in the intensity of use of materials and energy . Futures.1993, 25(4):431-448.

[5] Wernick, I. and J. H. Ausbel. National Material Flows and the Environment. Annual Review Energy Environment.1996,20:463-492.

[6] CHEN Xiao-qiu, ZHAO Ting-ting, GUO Yu-quan. Material input and output analysis of Chinese economy system. Scientiarum Naturalium University Pekinensis.2003, 39(4):538-547.

[7] Cutler J. Cleveland, Matthias Ruth. Indicator of Dematerialization and the Materials Intensity of use: A Critical Review with Suggestions for Future Research. Journal of industrial ecology. 1999, 2(3):15-50.

[8] Sun, J. W.. Changes in energy consumption and energy intensity: a complete decomposition model. Energy Economics.1998, 20(1):85-100.

[9] Sun, J. W., and MERISTO T.. Measurement of Dematerialization/Materialization: A Case Analysis of Energy Saving and Decarbonization in OECD Countries: 1960 1995[J].Technological Forecasting and Social Change.1999, 60:275 294.. 